\title{
Prevalence of premenstrual syndrome and quality of life among health science college student
}

\author{
Dwi Kustriyanti, Hermeksi Rahayu \\ Maternity Department, Science Health College of Karya Husada, Semarang, Indonesia
}

\begin{tabular}{l}
\hline \hline Article Info \\
\hline Article history: \\
Received Jan 13, 2020 \\
Revised Feb 15, 2020 \\
Accepted Feb 27, 2020 \\
\hline
\end{tabular}

\section{Keywords:}

Premenstrual syndrome

Prevalence

Quality of life

Student

\begin{abstract}
Premenstrual syndrome (PMS) is a set of affective, behavioral and physical symptoms with appear in the luteal phase that could affect productivity and quality of life. PMS in adolescents could affect academic performance, such as a decreasing in concentration, failed the exam and absenteeism in the class. The objective was to evaluate the prevalence of PMS and determine its effect on quality of life among female health science students. This cross-sectional study was conducted between July-September 2017 on nursing female students of Health Science Collage "Karya Husada Semarang", Central a Java, Indonesia. Students were enrolled 207 from first to fourth grade using WHOQOL-BREF form to determine quality of life. Inclusion criteria were having regular menstrual cycles (21-35 days) at least three period. Descriptive analysis and Mann Whitney tests were used for statistical analyses. The prevalence of PMS was found to be $60.8 \%$. Physical health, psychological, social relationship, and environment domain were significantly higher in females with PMS (for each one $P<0.05$ ).
\end{abstract}

This is an open access article under the CC BY-SA license.

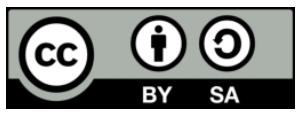

\section{Corresponding Author:}

Dwi Kustriyanti,

Maternity Department,

Science Health College of Karya Husada Semarang,

46 Kompol R. Soekanto Road, Tembalang, Semarang 50276, Central Java, Indonesia.

Email: dwikus3yanti@gmail.com

\section{INTRODUCTION}

Premenstrual syndrome (PMS) is a set of symptom that occurs repeatedly in the luteal phase of the menstrual cycle is marked by Chang of physical, psychology and behavior that may affect the relationship interpersonal [1-4]. PMS can occur several days to weeks before menstruation and subside after a menstrual period appears [5-6]. The impact of PMS also disrupts family relationships, work, social activities and difficulty in concentrating [7-9]. More than $85 \%$ of women had been experienced physical and psychological discomfort that may affect the quality of life and daily productivity [10-11]. The prevalence of PMS as much as $99.5 \%$ of adolescents had at least one premenstrual symptom [12-15]. The cause of PMS is unknown with certainty, it is estimated influencing by biological, psychological, and social environments. Biological factors include hormonal imbalance, abnormal neurotransmitter response [16, 18].

Symptom that is often complained by the teenagers is emotional symptoms such as irritability, depression, irritability, anxiety or tension, mood swings, while physical symptoms are breast tense, distended stomach, headache and fatigue [14-17]. In addition, PMS affects academic performance (60.1\%), teenagers leave school at least one day $(43.5 \%)$ and $22 \%$ fail in the exam [16, 19]. PMS also affects the efficiency and productivity, for instance homework (48.9\%), social activities (19.45\%), friends or family relationships (19.1\%), and difficulty concentrating (60.4\%) [18, 20]. Adolescents with PMS have lower 
learning achievement than those who did not have PMS. PMS also can affect the mental health and social life of an individual. Women with PMS often fail to go to work or school, resulting in an impaired quality of life.This is due to factors just before menstruation pain and hectic atmosphere [7, 21].

Physical, emotional and behavioral problem may exacerbate menstrual cycle problem and PMS. Nausea, vomitting, irritability symptoms are reported to have an impact on menstrual cycle. Due to this negative impact on an individual's quality of life may disrupted among adolescent women [22, 23]. The aim of this study was to evaluate the prevalence of PMS and its effect on quality of life (QOL) among students in Health Science College "Karya Husada Semarang”, Central Java, Indonesia.

\section{RESEARCH METHOD}

This study was conducted between July-Agustus 2017 among nursing female students of Health Science College "Karya Husada Semarang", Central Java, Indonesia. The sample size was determined by using single proportion for finite population with $95 \%$ confidence interval and marginal error (d) of $5 \%$. The questionnaire consist fourth part, the first part were asked to their socio-demographic, medical status and dysmenorrheal status and habits. The second part was The American College of Obstetrics and Gynecology (ACOG) criteria for PMS, DSM-IV for Premenstrual Dysphoric Disorder (PMDD) and WHOQOL-BREF form to measure quality of life of female students. WHOQOL- BREF consists of 26 items which provide assessment in four domain: physical, psychological, social relationships and environmental domain with values point from 1-5. The high scores obtained from the scale shows that the quality of life increases in positive ways.

\subsection{Population and Sample}

The populations were all female students of Health and Science College "Karya Husada Semarang", nursing faculty as many as 207 students from first until fourth grade. The sampling technique used was purposive sampling. Samples were taken based on inclusion criteria such as having regular menstrual cycles (21-35 days) at least two consecutive months, had fulfilled the questionnaires and willingness to participate. The exclusion criteriaa in this study were female students who has irregular menstrual cycle, had history of chronic illness, diabetes, heart disease or any other psychiatric disorder.

\subsection{Study Design}

This cross sectional study was conducted between July-Agustus 2017 on nursing female students of Health Science College "Karya Husada Semarang”, from first until fourth grade nursing faculty.

\subsection{Data Collection}

All 207 students surveyed at school completed the questionnaires and inventories during a class period. All subjects received explanation about procedural of study and how to fulfil the questionnaires. Before receiving any data, they gave their written informed consent to participate in the study. The initial screening of PMS or PMDD, students completed questionnaire by ACOG and DSMIV based on last period symptoms. Data were collected prospectively for two months using daily symptoms record which fulfilled the inclusion and exclusion criteria. Monitoring diary charging was done by sending message to the respondents in the afternoon assisted by student in charge of each class to remind each other to fill the diary. The first day of menstruation after being given a diary, they were asked to report to the person in charge of the class or researchers. Researchers examined the diary, if the students had those symptoms, so they were experienced with the criteria, then they fulfilled WHOQOL-BREF questionnaire to examine their quality of life.

\subsection{Data Analysis}

Statistical analyses were performed using the SPSS for windows version 16.00 (Statistical Package for Social Sciences Inc). Descriptive analytical parameters were used to summarize the socio demographic and clinical characteristics of the study participants. The different symptoms of PMS were presented, compared, analyzed and frequency distributions of the variable were interpreted. Chi square test was used to compare categorical variable and Mann Whitney test was used to compare the data with skewed distribution. Continues variables were presented as descriptive statistics such as mean \pm standard deviation, minimum and maximum value and percentages.

\subsection{Ethical Approval}

Permission for the study was obtained by making a prior petition to collecting data. This study was approved by Ethics Committee of Institute of Health and Science College of "Karya Husada Semarang" 
(Ref. No 15/UP3M/STIKES.KH/III/2017). All students gave their informed consent prior to their inclusion in the study.

\section{RESULTS AND DISCUSSION}

Characteristics of students' average (mean) age were 19, 17 and the mean age of menarche was 12.98 years old. Mean of the long period more than 6.79 days. Majority of female students complained deal with PMS (54\%), but the majority none (49,8\%). There was $4.3 \%$ students received massage and $18.4 \%$ consumed medication. Characteristics of the entire population can be seen in Table 1.

Tabel 1. Characteristics of Students with premenstrual syndrome $(n=126)$

\begin{tabular}{|c|c|c|c|c|}
\hline Characteristics & \multicolumn{4}{|c|}{ Population $(\mathrm{n}=126)$} \\
\hline & Mean \pm SD & Range & $\mathrm{f}$ & $\%$ \\
\hline Age (tahun) & $19.17 \pm 1.1180$ & $17-26$ & & \\
\hline Menarche (tahun) & $12.98 \pm 1.490$ & $10-17$ & & \\
\hline duration of periods & $6.79 \pm 1.852$ & $1-15$ & & \\
\hline Dysmenorrhea & & & 68 & 54 \\
\hline \multicolumn{5}{|c|}{ Type of treatments during premenstrual syndrome } \\
\hline 1. None & & & 103 & 49.8 \\
\hline 2. Medication & & & 38 & 18.4 \\
\hline Massase & & & 9 & 4.3 \\
\hline Herb mediacation & & & 32 & 15.5 \\
\hline
\end{tabular}

The highest premenstrual symptoms experienced by students were irritability; angry outburst and insomnia also decrease interest in usual activities. The most common physical symptom is breast tenderness and joins and muscle pain. PMS symptoms experienced by students were mostly disturbing in learning situations and relationships with friends. Another impact of these symptoms is that most students cannot learn effectively in school even though almost all of them continue to study in school. A description of the symptoms of each group can be seen in Table 2 .

Table 2. Premenstrual syndrome symptoms all students

\begin{tabular}{|c|c|c|c|c|c|c|c|}
\hline \multirow{2}{*}{ Premenstrual symptoms } & \multicolumn{2}{|c|}{ PMS } & \multicolumn{2}{|c|}{ PMDD } & \multicolumn{2}{|c|}{ Non PMS/PMDD } & \multirow{2}{*}{$P$ value } \\
\hline & $\mathrm{n}$ & $\%$ & $\mathrm{n}$ & $\%$ & $\mathrm{n}$ & $\%$ & \\
\hline \multicolumn{8}{|l|}{ Affective } \\
\hline Anxiety & 28 & 22.2 & 22 & 33.8 & 1 & 6.2 & 0.043 \\
\hline Depression & 5 & 4 & 3 & 4.6 & 3 & 18.8 & $0.044 *$ \\
\hline Had mood swing (e.g., suddenly felt sad or tearful) & 20 & 15.9 & 18 & 27.7 & 7 & 43.8 & 0.015 \\
\hline Irritability & 62 & 49.2 & 45 & 69.2 & 6 & 37.5 & 0.011 \\
\hline Fatigue & 62 & 49.2 & 34 & 52.3 & 9 & 56.2 & 0.828 \\
\hline Appetite changes (food craving) & 38 & 30.2 & 24 & 36.9 & 8 & 50 & 0.234 \\
\hline Insomnia & 32 & 25.4 & 10 & 15.4 & 11 & 68.8 & 0.000 \\
\hline Angry Outburst & 15 & 11.9 & 57 & 87.7 & 5 & 31.2 & 0.000 \\
\hline Poor concentration & 29 & 23 & 19 & 29.2 & 1 & 6.2 & 0.147 \\
\hline Decrease interest in usual activities & 36 & 28.6 & 22 & 33.8 & 9 & 56.2 & 0.080 \\
\hline \multicolumn{8}{|l|}{ Physical } \\
\hline Breast tenderness & 67 & 53.12 & 43 & 66.27 & 3 & 18.8 & 0.003 \\
\hline Headache & 14 & 11.48 & 11 & 16.9 & 5 & 31.2 & 0.078 \\
\hline Join and muscle pain & 61 & 48.4 & 31 & 47.7 & 6 & 37.5 & 0.711 \\
\hline Weight gain & 20 & 15.9 & 2 & 3.1 & 0 & 0 & 0.009 \\
\hline
\end{tabular}

Chi Square *Kruskal Wallis

The description of the quality of life of students differs based on the severity of premenstrual symptoms experienced. The quality of life among students has decreased in all domain, physical health, psychological, social relationships and environment. Description quality of life students can be seen in Table 3. Initial screening the prevalence of PMS were $151(63.7 \%)$ students who fulfilled the criteria for premenstrual syndrome by ACOG. These results indicated an increase in the prevalence of PMS from previous research, which was $47.3 \%$ [24]. Post-disaster areas had a higher prevalence than non-disaster one, such Merapi eruption affected psychological, such as anxiety, sleep disorders and post-disaster trauma [25]. In Japan, the prevalence of PMS in adolescents was relatively high at $64.6 \%$ but the prevalence was increasing in the disaster area after the earthquake became $85.6 \%[18,26]$. Previous research, also reported 
that $80.7 \%$ and $83.6 \%$ of adolescents had been experienced one or more symptoms of affective and somatic [17]. Compared with the prevalence of PMS in China that was equal to 21.1\%, which was not a disaster area, the prevalence showed a threefold increase [25].

Table 3. Quality of life of students each domain

\begin{tabular}{lccccccc}
\hline \multicolumn{1}{c}{ Domain } & \multicolumn{2}{c}{ PMS $(\mathrm{n}=126)$} & \multicolumn{2}{c}{ PMDD $(\mathrm{n}=65)$} & \multicolumn{2}{c}{ Non PMS/PMDD (n=16) } & \multirow{2}{*}{ P value } \\
& Mean \pm SD & min-max & Mean \pm SD & min-max & Mean \pm SD & min-max & \\
\hline Physical health & $41.38 \pm 8.52$ & $19-69$ & $30.95 \pm 11.43$ & $19-69$ & $68.56 \pm 9.20$ & $19-69$ & 0.000 \\
Psychological & $44.22 \pm 10.46$ & $19-75$ & $32.57 \pm 13.05$ & $6-81$ & $73.12 \pm 10.60$ & $19-63$ & 0.000 \\
Social relationships & $47.70 \pm 9.94$ & $31-81$ & $33.23 \pm 12.75$ & $19-94$ & $74.44 \pm 10.53$ & $25-56$ & 0.000 \\
Environment & $46.25 \pm 11.63$ & $19-69$ & $33.35 \pm 10.52$ & $13-69$ & $75.19 \pm 9.46$ & $31-88$ & 0.000 \\
\hline
\end{tabular}

Female students of Health Science College "Karya Husada Semarang” were majority (77.2\%) experienced during menstruation and had dysmenorrhea period more than 5 days $(84.8 \%)$. Physiologically dysmenorrhea occured before or during menstruation occurring at a young age and disappears after the first pregnancy [15, 22]. A long Dysmenorrhea and menstrual period were dtermined factors that could affect the PMS, the average student who had been experienced in PMS were more than 6 days [27]. There was a relationship between premenstrual syndrome with dysmenorrhea in adolescents, as many as $71 \%$ of adolescents experience dysmenorrhea and PMS and previous research also reported that the relatively high prevalence of dysmenorrhea was in line with PMS/PMDD [6, 23]. The prevalence of dysmenorrhea was as much as $63.7 \%$ in adolescents with low rate of PMS, $81.7 \%$ moderate PMS, and severe rate of PMS was as much as $81.7 \%$ by weight and $73.8 \%$ with PMDD.

Symptoms most commonly experienced were irritable, touchy, easily tired and anxious; while for the physical symptoms were often perceived breasts feel tight and sore muscles or joints. Previous research reported that symptoms of irritable been complained by teenagers in the amount of 58.5\% [16]. The Impact of premenstrual symptoms felt by the student could interfere their daily activities, disrupt learning activities even interfere in social interaction in touch with friends or family. Results observation reported that female students reported sometimes felt uncomfortable and should take rest in the infirmary and even asked permission not to attend school. Female students were often asking how to reduce the symptoms [28].

The studies assessing the perception of quality of life in women with PMS have shown that PMS impairs quality of life [29-30]. In our study, all score in phycological, social relationship and environment were lower in cases students with PMS. The quality of life was impaired by increased the severity of dysmenorrhea [27, 30]. In another study assessed the quality of life during menstrual period, where there were complaints of PMS and during the follicular phase. It was determined that the perception of quality of life was impaired during menstrual periods [29]. In our study determined that phycological health, social relationship and environment quality of life was lower in students with PMS. The Prevalence of premenstrual syndrome in adolescents in Helath Science College "Karya Husada Semarang" was 60.8\%. Characteristics of respondents with premenstrual syndrome of age aspect were such as the average (mean) of 19.17 years, the mean age of menarche of 12.98 years. The majority of respondents complained of dysmenorrhea as much as $54 \%$, yet the majority of the students consumed herbs and medicines (19.8\% and 19\%).

\section{CONCLUSION}

Premenstrual syndrome is a common health problem, having negative effects on the quality of life among female students of the health science collage.This research informs information regarding premenstrual syndrome (PMS) and its implication towards the quality life of students, thus which can give more advice about the related problem. The further researcher should take a wide sample and hold true experiment research that is needed in handling PMS among students.

\section{ACKNOWLEDGEMENT}

The authors are grateful to the maternity department of health science college "Karya Husada Semarang" and student's service of nursing study program for their unreserved cooperation in making this study to be fruitful work.

\section{REFERENCES}

[1] The American College of Obstetricians and Gynecologists. Frequenly Asked Question Gynecologic Problem, 2011. 
[2] Biggs, W.S., Demuth, R.H., "Premenstrual syndrome and premenstrual dysphoric disorder," American family physician, vol. 84. no. 8, 2011.

[3] Braverman, P.K, "Premenstrual Syndrome and Premenstrual Dysphoric Disorder," J. Pediatr Adolesc Gyneco, vol. 20, pp. 3-12, 2012.

[4] Yonkers, K.A., O’Brien, P.M.S., Erikson, E., "Premenstrual Syndrome”, Lancet, vol. 371, pp. 1200-10, 2008.

[5] Canning, S.E., Waterman, M.G., Simpson, N., Dye, L., "Reliability and component structure of modified Daily Symptom Report (DSR-20)," Journal of Reproductive and Infant Psychology, 2012.

[6] Steiner, M., Peer M., Palova, E., Freeman, E.W., Macdougall, M., Soares, C.N., "The premenstrual symptoms screening tool revised for adolescents (PSST-A): prevalence of severe PMS and premenstrual dysphoric disorder in adolescents," Arch Womens Ment Health, 2011.

[7] Obindo, T.S., Okeahialam, P.B.N., Ogbonna, C., "Violence Againts Women: is premenstrual syndrome a vulnerability factor?," Luter J Acad Res, vol. 2, pp. 153-6, 2010.

[8] Tolossa FW, Bekele ML., "Prevalence, Impacts and Medical Managements of Premenstrual Syndrome among Female Students: Cross-Sectional Study in College of Health Science, Mekelle University, Mekelle, Northern Ethiopia. BMC Women's Health, vol. 14, pp. 52, 2014.

[9] Yen, J.Y., Chang, S.J., Long, C.Y., Tang, T.C., Chen, C.C., Yen, C.F., "Working memory deficit in premenstrual dysporic disorder and its associations with difficulty in concentrating and irritability," Comprehensive psychiatry. DOI: 10.1016/j.comppsych. 2011.05.016, 2012.

[10] Pinar G, ColakM, Oksuz E., "Premenstrual Syndrome in Turkish College Students and Its Effects on Life Quality. Sex Reprod Health, vol. 2, pp. 21-27, 2011.

[11] Yang M, Wallenstein G, Hagan M, Guo A, Chang J, Korstein S., "Burden of Premenstrual Dysphoric Disorder on Health Related Quality of Life", J. Women's Healt, vol. 17, no. 1, pp. 113-122, 2008.

[12] Delara, M., Borzuei, H., Montazeri. A., "Premenstrual disorder: prevalence and associated factors in a sample of Iranian adolescent," Iranian Red Crescent Meidcal Journal, vol. 15, no. 8, pp. 695-700. DOI:10.5812/ircmj.2084. 2013

[13] Potter, J., Bouyer, J., Trussel, J., Moreau, C., "PMS prevalence and fluctuation over time: Results from a French Population-Based survey," Journal of Womens 's Health. Volume 18, No. 1. DOI: 10.1089/jwh.2008.0932, 2009.

[14] Qiao, M., Zhang, H., Liu, H., Luo, S., Wang, T., Zhang, J., Ji, L., "Prevalence of PMS and PMDD populationbased sample in China," European Journal of Obstetrics \& Gynecology and Reproductive Biollogy. DOI:10.1016/j.ejogrb.2012.01.017, 2012.

[15] Takeda, T., Koga, S., Yaegashi, N., "Prevalence of PMS and PMDD in Japanese high school students", Arch Womens Mental Health, 13:535-537. DOI: 10.1007/s00737-010-0181-3, 2010.

[16] Leppert. P.H., Peipert, J.F., "Primary Care for Women," Second edition. Philadelphia. Lippincott Williams and Wilkins, 2004.

[17] Attieh, E., Maalouf, S., Richa, S., Kesrouani, A., "PMS among Lebanese medical students and residents", International Federation of Gynecology and Obstetrics. vol. 121, no. 2, pp. 1879-3479, 2012.

[18] Wong, L.P., Khoo, E.M., "Menstrual-Related Attitude and Symptoms Among Multi-racial Asian Adolescent Females," International Journal Behavioral Medicine. 18:246-253. DOI 10.1007/s12529-010-9091-z, 2011.

[19] Heinemann, L.A.J., Minh, T.D., Filonenko, A., Hochgraber, K.U., "Explorative evaluation of the impact of severe premenstrual disorders on work absenteeism and productivity," Women's Health Issues, vol. 20, pp. 58-65, 2010.

[20] Kitamura, M., Takeda, T., Koga, S., Satoru, Yaegashi, N., "Relationship between premenstrual symptoms and dysmenorrheal in Japanese high school students," Arch Womens Ment Health. 15:131-133. DOI 10.1007/s00737012-0266-2, 2012.

[21] Kathleen M, Lustyk B, Gerrish WG., "Premenstrual Syndrome and Premenstrual Dysphoric Disorder: Issues of Quality of Life, Stress and Exercise," Springer Sci Bus Media LLC (USA). 115:1952-1975, 2010.

[22] Benson, R.C., Pernol, M.L. (2013). Buku saku Obstetri dan Ginekologi. Edisi 9. Jakarta: EGC.

[23] Charandabi, SMA., Biglu, MH., Yousefi, K., "Effect of Homeopathy on Pain Intensity and Quality of Life of Students with Primary Dysmenorrhea: Randomized Controlled Trial," J. Iran red Crescent Med., 18(9):e30902, 2016.

[24] Cahyanti, L., "Relation post traumatic stress disorder with prevalence of premenstrual syndrome and premenstrual dysphoric disorder in adolescents post eruption disaster," Thesis. Faculty of Medicine Gajah Mada University, 2012.

[25] Kustriyanti, D., "The Effect of Progressive Muscle Relaxation on Premenstrual syndrome in Senior High School 1 Cangkringan Yogyakarta,” Master's thesis Nursing Science Graduate Studies, Gajah Mada University, 2015.

[26] Takeda, T., Tadakawa, M., Koga, S., Nagase, S., Yaegashi, N., "Premenstrual symptoms and posttraumatic stress disorder in Japanese High School: students 9 months after the great East-Japan earthquake," Tohoku Journal Exp. Med. 230: 151-154. DOI: 10.1620/tjem.230.151, 2013.

[27] Pilliteri. A., "Maternal and Child Health Nursing," $6^{\text {th }}$ edition. Wolter Kluwer. New York, 2010.

[28] Delara, M., Ghofranipour, F., Azadfallah, P., Tavafian, S.S., Kazemnajed, A., "Health related quality of life among adolescents with premenstrual disorder: across sectional study". Health and quality of life outcome. 10:1. 2012. [Online] Aviable: http://www.hqio.com/content/10/1/1

[29] Lacodives S., Avidon I, Bentley A, Baker FC., "Reduced quality of life when experiencing menstrual pain in women with primary dysmenorrhea," Acta Obstet Gynecol Scand, vol. 93, no. 2, pp. 213-7, 2014.

[30] Unsal A, Ayranci U, Tozun M, arslan G, Calik E., "Prevalence of dysmenorrhea and its effect on quality of life among a group of female university students," Ups J Med Sci. vol. 15, pp. 138-45, 2010. 